EREM 77/3

Journal of Environmental Research, Engineering and Management Vol. 77 / No. 3 / 2021 pp. 99-107 DOI 10.5755/j01.erem.77.3.23720
Biotic Relations Between Pathogenic Leptospires and Green Algae

Received 2019/06

Accepted after revision 2021/08

\title{
Biotic Relations Between Pathogenic Leptospires and Green Algae
}

\author{
Hulai Oleksandr*, Hulai Vitalii \\ Volodymyr Vynnychenko Central Ukrainian State Pedagogical University, \\ Shevchenko 1, Kropivnitskiy, 25006, Ukraine
}

\section{Tkachuk Nataliia}

Ukrainian National Academy of Science, Institute of Agroecology and Environmental Sciences,

Metrologichna 12, Kyiv, 03143, Ukraine

*Corresponding author: ol.gulay42@gmail.com

Leptospira interrogans spirochetes belong to a group of pathogens of particularly dangerous infections that cause leptospirosis in many species of wild, farm and domestic animals, as well as humans. Significant economic damage caused by this disease to livestock around the world, numerous cases of death from leptospirosis, and mainly waterborne transmission of the infection determine the topicality of studying all the aspects of the existence of $L$. interrogans in freshwater ecosystems. The objective of our study was to determine the nature of ecological relationships between $L$. interrogans and green algae. We used green algae of the Desmodesmus brasiliensis species as a model object. In the experiments, sterile algae culture filtrates were added to $L$. interrogans containers grown at $27-28{ }^{\circ} \mathrm{C}$. Comparison of the content of spirochete cells in the experiment and control samples, conducted 24 hours after exposure, showed that the reproduction of $L$. interrogans is markedly inhibited in the samples containing algae secretions at the dilutions of 1:10 and 1:100. In order to reduce resistance to the allelopathic influence of $D$. brasiliensis algae, leptospira strains were located as follows: Pomona, Australis, Hebdomadis, Canicola, Sejroe, Icterohaemorrhagiae, Grippotyphosa, Tarassovi. The obtained results indicate a complex intraspecific structure of $L$. interrogans and their high ecological plasticity. In addition, experimental data indicate that, due to the release of biologically active substances into the aquatic environment, green algae have the potential to affect the dynamics of a number of leptospirosis pathogens in situ. Given the important epidemiological and epizootic significance of pathogenic leptospira, further research is necessary to determine the patterns of their interactions and existence in the environment.

Keywords: Leptospira interrogans, green algae, allelopathic influence, Desmodesmus brasiliensis. 


\section{Introduction}

A number of pathogens of dangerous human and animal diseases can penetrate the new nourisher's body with water. Spirochetes of the species Leptospira interrogans (Stimson, 1907) Wenyon, 1926 emend. Faine and Stallman, 1982 (Faine, Stallman, 1982), are among them, causing an infectious disease known as leptospirosis. By appearance, Leptospira are delicate, thin, spiral form, single-celled microorganisms. Their length reaches 6-20 microns, and the diameter is about 0.1 microns. Active mobility is a characteristic feature of leptospira, helping these pathogenic microorganisms to penetrate into the host's body due to minor damage to the skin or damage to the mucous membranes, as well as to overcome bacterial filters. These spirochetes are characterized by a rather complex intraspecific structure. L. interrogans species is represented by 202 serological variants, which are combined into 23 serological groups by the degree of antigenic affinity. Leptospira are gram-negative microorganisms, having no spores and capsules. By morphology, both pathogenic and saprophytic agents isolated from a human or different species of animals do not differ from one another regardless of their belonging to different serological groups (Bharti et al., 2003; Levett, 2001).

Cases of leptospirosis are registered in all parts of the world inhabited by humans (Vinetz, 2001; Xiao-Juan Ma et al., 2020; Piredda et al., 2021; Philip et al., 2020; Mahtab et al., 2019; Alinaitwe et al., 2019), except Antarctica. Pathogenic leptospira can parasitize in organisms of many species of domestic and wild animals of various systematic and ecological groups. Thus, according to scientific literature, $L$. interrogans were found in mammals, birds, reptiles, amphibians, fish and invertebrates. In many of these animals, pathogenic leptospira is stored in the body during their lifetime and periodically excreted mainly with urine, even though these animals look clinically healthy. It is particularly dangerous when domestic and farm animals - pigs, cattle, horses, goats, sheep, dogs, cats, etc. - are carriers of the disease. Leptospirosis causes significant economic loss to livestock farms around the world, which is associated with the cost of disease prevention, the treatment of sick animals, abortion, death of young animals, infertility, and reduced animal productivity.

According to the existing classifications, leptospirosis belongs to the group of natural and focal diseases, so $L$. interrogans can circulate over a long period of time among different representatives of wild fauna and objects of the environment (water, soil) without human interference. As a result, foci of the disease are formed, in which the existence of these pathogenic microorganisms and their distribution on the adjacent territory are supported. Quite often, such foci are concentrated around water bodies or drenched areas. As already noted, fresh water in open reservoirs is one of the main ways of spreading pathogenic leptospira. Numerous studies have shown that $L$. interrogans spirochetes can survive in fresh water for a long time. In particular, there are certain data that leptospira survive in water up to 150 days. However, according to many researchers, their longevity and the possibility of reproduction of pathogenic leptospira in fresh water are determined not only by the chemical composition of water, but also (and to a much greater extent) by the specific ecological connections between $L$. interrogans and numerous species of hydrobionts. For example, some researches (Hulai, 2005) show that various species of freshwater filtration bacteriotrophs (infusoria, rotifers, crustaceans, mosquitoes, molluscs, insect larvae) actively remove leptospira from the aquatic environment. In addition, ecological connections of leptospira with numerous species of higher plants, growing in water reservoirs, coastal areas and water-logged lands (Hulai, 2010), are revealed. It has been proved that plants can influence the population of pathogenic leptospira due to the release of various biologically active substances in the environment, as a result of which spirochetes density can be changed significantly in comparison with the control samples. The results of experiments suggest that spirochetes can demonstrate significant fluctuations in their number in the natural conditions of population, which are caused by allelopathic effects on the part of numerous species of plants. Taking into account the potential danger of $L$. interrogans as a causative agent of human and animal diseases, the information about the factors leading to significant changes in the number or survivability of this species of spirochetes in the aquatic environment is of great practical importance.

The analysis of scientific literature showed that there is a significant gap in the information about the environmental interaction between pathogenic leptospira and green algae (Chlorophyta), which is an important group of aquatic plants. It is known that green algae often act 
as a dominant group of plants in freshwater plankton. Besides, there is a variety of different biologically active substances (Hasbi et al., 2021; Bhuyar et al., 2020). However, despite this fact, the researches on the interactions of various species of green algae with pathogenic leptospira are extremely insufficient. In particular, we have found only two publications on this topic. The first one was on the positive effect of green algae on pathogenic leptospira, and blue-green algae (cyanobacteria) being their antagonists (Trop, 1976). However, this publication does not indicate any species name of algae and does not provide any description of the experiments or their results. The other publication presents the results of studying the allelopathic effect of three types of green algae macrophytes (Hulai, 2003) on 7 serological types of leptospira. According to these data, water-soluble excretions of algae can influence population density dynamics of pathogenic leptospira under experimental conditions. Taking into account the considerable variety of green algae species, further study of their interaction with $L$. interrogans pathogenic spirochetes seems substantiated. The main objective of the research is to obtain valuable practical, scientifically proven data that could be used in the implementation of measures aimed at reducing the potentials of natural foci of leptospirosis and preventing the infection of humans, domestic and wild animals.

Desmodesmus brasiliensis (Bohlin) E. Hegew is one of the most common types of microscopic green algae in the water reservoirs of Ukraine. The experiment was aimed at studying the allelopathic effect of the excretions of algae $D$. brasiliensis on the density of pathogenic leptospira of the most common serological variants in Ukraine.

\section{Methods}

\section{Algae and bacterial strains}

The research was based on algal-pure green algae cultures from the collection of the Institute of Hydrobiology of the National Academy of Sciences of Ukraine (Kyiv). The monocultures of Desmodesmus brasiliensis green algae were cultivated for 7-10 days in $250 \mathrm{~cm}^{3}$ Erlenmeyer flasks inside the Fitzgerald mineral medium in modifications by Zehnder and Gorham at the temperature of $22-25{ }^{\circ} \mathrm{C}$, with a 12-hour photoperiod, and under the artificial light of daylight fluorescence 25 Kcal lamps.

Experiments were carried out on the basis of the leptospirosis laboratory with a collection of microorganism strains from the Institute of Veterinary Medicine of the National Academy of Agrarian Sciences of Ukraine (Kyiv). Leptospira were cultivated at the temperature of $27-28{ }^{\circ} \mathrm{C}$ on the Terskih and Korthof nutrient medium containing $10 \%$ of the inactivated sheep's blood serum.

The experiment involved 7 to 14-day-old spirochete cultures with the accumulation of 50-100 leptospira in the field of view of a microscope, with characteristic morphology, active mobility and no signs of autoagglutination. Taking into account that the $L$. interrogans species has a large number of serological variants, a set of strains of these microorganisms used in the laboratories of Ukraine as an antigen for serological diagnostics of leptospirosis in humans and animals (Table 1) was used in experiments.

Table 1. L. interrogans spirochetes stock cultures chosen for the experiments

\begin{tabular}{|c|c|c|c|c|}
\hline № & Serogroup & Serovariant & Stock Culture & Abbreviation \\
\hline 1 & Sejroe & pollonica & 493 Poland & Sejroe \\
\hline 2 & Hebdomadis & kabura & Kabura & Hebdomadis \\
\hline 3 & Tarassovi & tarassovi & Perepelicyn & Tarassovi \\
\hline 4 & Pomona & pomona & Pomona & Pomona \\
\hline 5 & Grippotyphosa & grippotyphosa & Moskva V & Grippotyphosa \\
\hline 6 & Canicola & canicola & Hond Utrecht IV & Canicola \\
\hline 7 & Icterohaemorrhagiae & copenhageni & M20 & Icterohaemorrhagiae \\
\hline 8 & Australis & bratislava & Yez bratislava & Australis \\
\hline
\end{tabular}




\section{Preparation of algae influence}

The experiments were conducted in vitro, simulating the conditions of aquatic ecosystems. The study of the influence of green algae on pathogenic leptospira was carried out with the help of the biotesting method. The presence of background and symbiotic microflora in the samples is undesirable because it introduces significant changes in the research results. In this regard, the resulting aquatic solutions of algal isolates should be sterilized in a way that would make it impossible to destroy the biologically active substances. Our needs are most thoroughly met by the sterilization method of aquatic solutions through filtration with cellulose filters, the pore diameter being 0.2 $\mu \mathrm{m}$ (Sartorius, Germany).

Experimental samples contained the filtrates with $D$. brasiliensis isolations in the dilutions of 1:10, 1:100, 1:1,000 and 1:10,000. The Fitzgerald sterile nutrient medium in modifications by Zehnder and Gorham was used for obtaining dilutions of isolate filtrates and for their control.

\section{Determination growth rate leptospira}

Inocula for control and experimental samples were taken from a single leptospira culture of a specific serological variant. Thus, the initial density of leptospira in the samples for each serological variant was the same. The experiments were carried out in five repetitions. Spirochetes were recorded in the samples 24 hours after the experiment had begun. The density of leptospira cells was determined by direct counting. The MBR-1 microscope with the $\mathrm{OI}-13$ darkfield condenser was used for microscopy analysis of the samples.

The evaluation of green algae isolates effect on $L$. interrogans was carried out by comparing the content of leptospira in the experiment and control samples, the content of cells in the control samples taken for $100 \%$.

\section{Results and Discussion}

The data obtained in the course of experiments aimed at studying the effect of algae $D$. brasiliensis isolations in 1:10 dilution on the cultures of experimental serological variants of pathogenic leptospira are given in Table 2. The analysis of the obtained results showed that the leptospira density in the experimental samples decreased during 24 hours, as compared with the control ones, indicating the bacteriostatic effect of the culture filtrates of $D$. brasiliensis green algae on the experimental spirochete cultures. Attention is drawn to the fact that the inhibition rates of $L$. interrogans used in the studies of serological variants were somewhat different. In particular, if the serological variants of leptospira are ranked according to the increase in their inhibition potential, the following can be obtained: Icterohaemorrhagiae (30.2\%,) Sejroe (36.9\%), Canicola (39.8\%),

Table 2. Density of $L$. interrogans cells in experimental and control samples under the influence of $D$. brasiliensis culture filtrates in 1:10 dilution

\begin{tabular}{|c|c|c|c|c|c|c|c|c|}
\hline \multirow{3}{*}{$\begin{array}{c}\text { No of } \\
\text { experiment }\end{array}$} & \multicolumn{8}{|c|}{ L. interrogans cell density, $\times 10^{6} / \mathrm{cm}^{3}$} \\
\hline & \multicolumn{2}{|c|}{ Sejroe } & \multicolumn{2}{|c|}{ Hebdomadis } & \multicolumn{2}{|c|}{ Tarassovi } & \multicolumn{2}{|c|}{ Pomona } \\
\hline & Test & Control & Test & Control & Test & Control & Test & Control \\
\hline 1 & 5.60 & 8.30 & 2.40 & 4.40 & 6.60 & 11.80 & 4.50 & 9.40 \\
\hline 2 & 5.30 & 8.70 & 2.00 & 4.50 & 5.80 & 13.10 & 4.30 & 10.30 \\
\hline 3 & 5.40 & 9.20 & 2.10 & 4.00 & 6.90 & 14.60 & 4.10 & 9.30 \\
\hline 4 & 5.10 & 8.50 & 2.40 & 4.20 & 5.40 & 12.50 & 4.00 & 10.10 \\
\hline 5 & 5.70 & 8.30 & 2.30 & 4.30 & 7.10 & 14.00 & 4.30 & 10.40 \\
\hline$M^{*}$ & 5.42 & 8.60 & 2.24 & 4.28 & 6.36 & 13.20 & 4.24 & 9.90 \\
\hline$t^{*}$ & \multicolumn{2}{|c|}{16.02} & \multicolumn{2}{|c|}{17.24} & \multicolumn{2}{|c|}{11.41} & \multicolumn{2}{|c|}{22.99} \\
\hline
\end{tabular}

$t_{\mathrm{kP}}^{*}=5.04 ; P^{*}<0.001$

${ }^{*}$ Note. $M$ - Arithmetic average; $t$-Student's coefficient; $t_{c r}=$ Critical value of characteristic $t$; $P$ - Probability level 
End of Table 2

\begin{tabular}{|c|c|c|c|c|c|c|c|c|}
\hline \multirow{3}{*}{$\begin{array}{l}\text { No of } \\
\text { experiment }\end{array}$} & \multicolumn{8}{|c|}{ L. interrogans cell density, $\times 10^{6} / \mathrm{cm}^{3}$} \\
\hline & \multicolumn{2}{|c|}{ Grippotyphosa } & \multicolumn{2}{|c|}{ Canicola } & \multicolumn{2}{|c|}{ Icterohaemorrhagiae } & \multicolumn{2}{|c|}{ Australis } \\
\hline & Test & Control & Test & Control & Test & Control & Test & Control \\
\hline 1 & 9.80 & 18.60 & 6.70 & 11.20 & 4.00 & 6.10 & 6.40 & 12.90 \\
\hline 2 & 10.80 & 19.10 & 7.50 & 10.70 & 4.20 & 5.50 & 5.90 & 11.00 \\
\hline 3 & 10.50 & 18.00 & 6.90 & 12.00 & 3.90 & 5.90 & 6.50 & 13.20 \\
\hline 4 & 9.20 & 15.90 & 6.60 & 11.50 & 3.80 & 5.30 & 6.80 & 11.50 \\
\hline 5 & 10.30 & 17.30 & 7.10 & 12.30 & 4.20 & 6.00 & 6.20 & 13.70 \\
\hline M & 10.12 & 17.78 & 6.96 & 11.54 & 4.02 & 5.76 & 6.36 & 12.46 \\
\hline $\mathrm{t}$ & \multicolumn{2}{|c|}{12.25} & \multicolumn{2}{|c|}{14.05} & \multicolumn{2}{|c|}{10.05} & \multicolumn{2}{|c|}{11.34} \\
\hline
\end{tabular}

$t_{\mathrm{kP}}=5.04 ; P<0.001$

Grippotyphosa (43.1 \%), Hebdomadis (42.4\%), Australis (48.5\%), Tarassovi (51.7\%), Pomona (56.6\%).

In the next group of experimental samples, which contained the culture medium of $D$. brasiliensis algae in 1:100 dilution, the spirochete inhibition rates were somewhat lower. In particular, the serological groups of leptospira were ranked according to the increase of their inhibition rate: Icterohaemorrhagiae (18.7\%), Seyroe (22.3\%), Canicola (25. 3\%), Grippotyphosa (27.6\%), Hebdomadis (31.0\%), Australis (37.4\%), Tarassovi (39.5\%), Pomona (44.9\%).
In the samples, containing the culture medium of $D$. brasiliensis algae in 1:1000 dilution, the following inhibition rate of leptospira cultures was recorded: Icterohaemorrhagiae (10.2\%), Grippotyphosa (11.9\%), Canicola (12.0\%), Seyroe (13.8\%), Hebdomadis (17.7\%), Australis (19.6\%), Tarassovi (22.4\%), Pomona (28.1\%). When comparing the contents of spirochetes in experimental and control samples containing algae cultures in 1:10 000 dilution, no significant statistical difference was found.

Table 3. Density of $L$. interrogans cells in experimental and control samples under the influence of $D$. brasiliensis culture filtrates in 1:100 dilution

\begin{tabular}{|c|c|c|c|c|c|c|c|c|}
\hline \multirow{3}{*}{$\begin{array}{c}\text { No of } \\
\text { experiment }\end{array}$} & \multicolumn{8}{|c|}{ L. interrogans cell density, $\times 10^{6} / \mathrm{cm}^{3}$} \\
\hline & \multicolumn{2}{|c|}{ Sejroe } & \multicolumn{2}{|c|}{ Hebdomadis } & \multicolumn{2}{|c|}{ Tarassovi } & \multicolumn{2}{|c|}{ Pomona } \\
\hline & Test & Control & Test & Control & Test & Control & Test & Control \\
\hline 1 & 7.00 & 8.30 & 3.00 & 4.40 & 8.70 & 11.80 & 5.10 & 9.40 \\
\hline 2 & 7.20 & 8.70 & 2.80 & 4.50 & 8.40 & 13.10 & 5.40 & 10.30 \\
\hline 3 & 6.90 & 9.20 & 3.10 & 4.00 & 7.30 & 14.60 & 5.80 & 9.30 \\
\hline 4 & 6.10 & 8.50 & 2.90 & 4.20 & 8.00 & 12.50 & 5.30 & 10.10 \\
\hline 5 & 6.40 & 8.30 & 3.10 & 4.30 & 7.60 & 14.00 & 5.50 & 10.40 \\
\hline M & 6.72 & 8.60 & 2.98 & 4.28 & 8.00 & 13.20 & 5.42 & 9.90 \\
\hline$t$ & \multicolumn{2}{|c|}{7.14} & \multicolumn{2}{|c|}{12.51} & \multicolumn{2}{|c|}{9.22} & \multicolumn{2}{|c|}{17.39} \\
\hline
\end{tabular}


End of Table 3

\begin{tabular}{|c|c|c|c|c|c|c|c|c|}
\hline \multirow{3}{*}{$\begin{array}{c}\text { No of } \\
\text { experiment }\end{array}$} & \multicolumn{8}{|c|}{ L. interrogans cell density, $\mathrm{x} 10^{6} / \mathrm{cm}^{3}$} \\
\hline & \multicolumn{2}{|c|}{ Grippotyphosa } & \multicolumn{2}{|c|}{ Canicola } & \multicolumn{2}{|c|}{ Icterohaemorrhagiae } & \multicolumn{2}{|c|}{ Australis } \\
\hline & Test & Control & Test & Control & Test & Control & Test & Control \\
\hline 1 & 14.10 & 18.60 & 9.10 & 11.20 & 4.30 & 6.10 & 8.30 & 12.90 \\
\hline 2 & 12.20 & 19.10 & 9.40 & 10.70 & 4.50 & 5.50 & 7.70 & 11.00 \\
\hline 3 & 11.40 & 18.00 & 8.80 & 12.00 & 4.70 & 5.90 & 7.20 & 13.20 \\
\hline 4 & 12.50 & 15.90 & 7.80 & 11.50 & 4.50 & 5.30 & 8.10 & 11.50 \\
\hline 5 & 13.70 & 17.30 & 8.10 & 12.30 & 4.90 & 6.00 & 7.50 & 13.70 \\
\hline M & 12.78 & 17.78 & 8.64 & 11.54 & 4.58 & 5.76 & 7.76 & 12.46 \\
\hline $\mathrm{t}$ & \multicolumn{2}{|c|}{6.70} & \multicolumn{2}{|c|}{7.01} & \multicolumn{2}{|c|}{6.40} & \multicolumn{2}{|c|}{8.49} \\
\hline
\end{tabular}

Table 4. Density of $L$. interrogans cells in experimental and control samples under the influence of $D$. brasiliensis culture filtrates in 1:1000 dilution

\begin{tabular}{|c|c|c|c|c|c|c|c|c|}
\hline \multirow{3}{*}{$\begin{array}{c}\text { No of } \\
\text { experiment }\end{array}$} & \multicolumn{8}{|c|}{ L. interrogans cell density, $x$ 106/cm3 } \\
\hline & \multicolumn{2}{|c|}{ Sejroe } & \multicolumn{2}{|c|}{ Hebdomadis } & \multicolumn{2}{|c|}{ Tarassovi } & \multicolumn{2}{|c|}{ Pomona } \\
\hline & Test & Control & Test & Control & Test & Control & Test & Control \\
\hline 1 & 7.60 & 8.30 & 3.70 & 4.40 & 10.10 & 11.80 & 7.30 & 9.40 \\
\hline 2 & 7.20 & 8.70 & 3.30 & 4.50 & 11.20 & 13.10 & 6.60 & 10.30 \\
\hline 3 & 7.50 & 9.20 & 3.50 & 4.00 & 9.90 & 14.60 & 7.20 & 9.30 \\
\hline 4 & 7.80 & 8.50 & 3.80 & 4.20 & 9.30 & 12.50 & 6.90 & 10.10 \\
\hline 5 & 7.10 & 8.30 & 3.40 & 4.30 & 10.50 & 14.00 & 7.60 & 10.40 \\
\hline$M$ & 7.44 & 8.60 & 3.54 & 4.28 & 10.20 & 13.20 & 7.12 & 9.90 \\
\hline$t$ & \multicolumn{2}{|c|}{5.49} & \multicolumn{2}{|c|}{5.85} & \multicolumn{2}{|c|}{5.05} & \multicolumn{2}{|c|}{9.68} \\
\hline
\end{tabular}

$t_{k p}=3.36 ; P<0.01$

End of Table 4

\begin{tabular}{|c|c|c|c|c|c|c|c|c|}
\hline \multirow{3}{*}{$\begin{array}{c}\text { No of } \\
\text { experiment }\end{array}$} & \multicolumn{8}{|c|}{ L. interrogans cell density, $\times 10^{6} / \mathrm{cm}^{3}$} \\
\hline & \multicolumn{2}{|c|}{ Grippotyphosa } & \multicolumn{2}{|c|}{ Canicola } & \multicolumn{2}{|c|}{ Icterohaemorrhagiae } & \multicolumn{2}{|c|}{ Australis } \\
\hline & Test & Control & Test & Control & Test & Control & Test & Control \\
\hline 1 & 16.60 & 18.60 & 10.40 & 11.20 & 5.30 & 6.10 & 10.10 & 12.90 \\
\hline 2 & 15.30 & 19.10 & 10.90 & 10.70 & 5.10 & 5.50 & 9.20 & 11.00 \\
\hline 3 & 16.10 & 18.00 & 10.60 & 12.00 & 4.90 & 5.90 & 10.70 & 13.20 \\
\hline 4 & 14.80 & 15.90 & 9.20 & 11.50 & 4.80 & 5.30 & 10.40 & 11.50 \\
\hline 5 & 15.40 & 17.30 & 9.70 & 12.30 & 5.50 & 6.00 & 9.30 & 13.70 \\
\hline M & 15.64 & 17.78 & 10.16 & 11.54 & 5.12 & 5.76 & 9.94 & 12.46 \\
\hline$t$ & \multicolumn{2}{|c|}{3.33} & \multicolumn{2}{|c|}{3.28} & \multicolumn{2}{|c|}{3.2} & \multicolumn{2}{|c|}{4.23} \\
\hline
\end{tabular}


Table 5. Density of L. interrogans cells in experimental and control samples under the influence of D. brasiliensis culture filtrates in 1:10 000 dilution

\begin{tabular}{|c|c|c|c|c|c|c|c|c|}
\hline \multirow{3}{*}{$\begin{array}{c}\text { No of } \\
\text { experiment }\end{array}$} & \multicolumn{8}{|c|}{ L. interrogans cell density, $\times 10^{6} / \mathrm{cm}^{3}$} \\
\hline & \multicolumn{2}{|c|}{ Sejroe } & \multicolumn{2}{|c|}{ Hebdomadis } & \multicolumn{2}{|c|}{ Tarassovi } & \multicolumn{2}{|c|}{ Pomona } \\
\hline & Test & Control & Test & Control & Test & Control & Test & Control \\
\hline 1 & 8.10 & 8.30 & 3,90 & 4.40 & 10.70 & 11.80 & 8.70 & 9.40 \\
\hline 2 & 7.50 & 8.70 & 4,10 & 4.50 & 13.00 & 13.10 & 8.50 & 10.30 \\
\hline 3 & 8.80 & 9.20 & 3,90 & 4.00 & 13.20 & 14.60 & 9.10 & 9.30 \\
\hline 4 & 8.30 & 8.50 & 4,00 & 4.20 & 11.90 & 12.50 & 8.80 & 10.10 \\
\hline 5 & 7.90 & 8.30 & 3,80 & 4.30 & 12.40 & 14.00 & 7.90 & 10.40 \\
\hline M & 8.12 & 8.60 & 3,94 & 4.28 & 12.24 & 13.20 & 8.60 & 9.90 \\
\hline$t$ & \multicolumn{2}{|c|}{1.76} & \multicolumn{2}{|c|}{3.40} & \multicolumn{2}{|c|}{1.43} & \multicolumn{2}{|c|}{1.26} \\
\hline
\end{tabular}

$t_{\mathrm{kp}}=2.31 ; \mathrm{P}<0.05$

End of Table 5

\begin{tabular}{|c|c|c|c|c|c|c|c|c|}
\hline \multirow{3}{*}{$\begin{array}{c}\text { No of } \\
\text { experiment }\end{array}$} & \multicolumn{8}{|c|}{ L. interrogans cell density, $\times 10^{6} / \mathrm{cm}^{3}$} \\
\hline & \multicolumn{2}{|c|}{ Grippotyphosa } & \multicolumn{2}{|c|}{ Canicola } & \multicolumn{2}{|c|}{ Icterohaemorrhagiae } & \multicolumn{2}{|c|}{ Australis } \\
\hline & Test & Control & Test & Control & Test & Control & Test & Control \\
\hline 1 & 15.90 & 18.60 & 10.10 & 11.20 & 5.40 & 6.10 & 10.70 & 12.90 \\
\hline 2 & 18.10 & 19.10 & 11.90 & 10.70 & 5.50 & 5.50 & 12.20 & 11.00 \\
\hline 3 & 17.50 & 18.00 & 11.30 & 12.00 & 5.70 & 5.90 & 11.40 & 13.20 \\
\hline 4 & 16.40 & 15.90 & 12.50 & 11.50 & 5.00 & 5.30 & 10.00 & 11.50 \\
\hline 5 & 17.30 & 17.30 & 9.80 & 12.30 & 5.30 & 6.00 & 11.60 & 13.70 \\
\hline M & 17.04 & 17.78 & 11.12 & 11.54 & 5.38 & 5.76 & 11.18 & 12.46 \\
\hline$t$ & \multicolumn{2}{|c|}{1.08} & \multicolumn{2}{|c|}{0.71} & \multicolumn{2}{|c|}{1.98} & \multicolumn{2}{|c|}{2.0} \\
\hline
\end{tabular}

$\mathrm{t}_{\mathrm{kp}}=2.31 ; \mathrm{P}<0.05$

In our opinion, the obtained data are of important epidemiological and epizootological significance, as they reveal new aspects of the existence and functioning of natural and anthropogenic foci of leptospirosis. Until now, when analyzing the potential of leptospirosis foci, scientists and practitioners have paid special attention to warm-blooded carriers of pathogenic leptospira, mainly rodents and farm animals (pigs, cattle, etc.). However, the existence of leptospira in water conditions did not receive enough attention and was mainly restricted to measuring the $\mathrm{pH}$ level of water, because leptospira are known to be quite sensitive to the acid reaction of the environment. So far, we have obtained convincing evidence that pathogenic leptospira are able to form ecological relationships with other representatives of the freshwater ecosystems biota - algae. Experiments have shown that leptospira change their number depending on the concentration of biologically active substances released by algae in the environment. This allows us to consider the reservoir not as a homogeneous environment for the favorable existence of these infectious agents, but on the contrary, as a complex and dynamic system both in space and time. It is not difficult to imagine that the concentration of substances released by algae will decrease further away from the place of their mass reproduction, and this, accordingly, will affect the conditions for the existence of pathogenic leptospira. There are changes in the species composition of algae groups in the reservoirs during the year, which are known to affect the dynamics of the amount of leptospira. 
In addition, the effect of varying sensitivity to allelopathic influence of the algae used in the experiments of serological types of leptospira has been revealed. It is known that the etiological structure of leptospirosis in animals and humans may differ markedly in various areas, which is usually associated with the differences in the fauna of potential carriers of leptospira, mostly small mammals. Without denying this fact, we consider it necessary to emphasize that the dynamics of algal groups in the study area may have some significance in the formation of the etiological structure of leptospirosis.

The possibility of reducing the potential of leptospirosis foci within small bodies of water should not be ruled out in case of creating favorable conditions for the reproduction of certain species of algae. They will have the greatest negative impact on a particular serological type of leptospira that dominates the area. Such environmentally friendly methods of removing pathogens from environmental objects have significant prospects. However, for the purpose of their development and implementation, it is necessary to conduct a number of studies on the interaction of pathogenic leptospira with other species of algae and other aquatic organisms.

Thus, taking into account the possibility of allelopathic influence of algae on the dynamics of the population of leptospira in aquatic ecosystems, as well as the differences in sensitivity to the effect of their different serological types, makes it possible to adopt a new approach to understanding and analyzing the existence and functioning of the dangerous infection of leptospirosis.

It is quite possible that the uneven conditions of existence for pathogenic microorganisms form the basis of the known effect of "natural foci" and other infections, which is due to the specificity of plant communities and their allelopathic effects.

Given the important epidemiological and epizootic significance of pathogenic leptospira, further research is necessary to determine the patterns of their interactions and existence in the environment.

\section{References}

Alinaitwe L., Kankya C., Namanya D., Pithua P., Dreyfus A. (2020) Leptospira Seroprevalence Among Ugandan Slaughter Cattle:

\section{Conclusions}

1 The isolations of $D$. brasiliensis green algae in dilutions from 1:10 and up to 1:1000 have a negative influence on $L$. interrogans cultures, which was manifested at significantly lower contents of spirochete cells in the experimental samples compared with the control ones.

2 Under experimental conditions, pathogenic leptospira did not respond by changing the culture density to the presence of biologically active substances in the medium produced by the $D$. brasiliensis algae in 1:10 000 dilution of their culture filtrates.

3 The reaction of the serological variants of $L$. interrogans spirochetes used in the studies to the influence of biologically active substances produced by the $D$. brasiliensis green algae was somewhat different. The strains of leptospira were ranked according to the decrease in the resistance of algae isolates: Icterohaemorrhagiae, Sejroe, Canicola, Grippotyphosa, Hebdomadis, Australis, Tarassovi, Pomona. This indicates the complex intraspecific structure of $L$. interrogans and their high ecological plasticity.

4 The obtained experimental results suggest that ecological connections of the topical type are formed in the natural foci of leptospirosis between $L$. interrogans spirochetes and $D$. brasiliensis green algae.

5 The discovered ability of green algae to inhibit the reproduction of pathogenic leptospira may have practical implications in the development of methods for the rehabilitation of environmental objects from pathogens. However, in order to clarify a number of important issues, it is necessary to conduct a series of studies and make observations on the interaction of pathogenic leptospira with other types of green algae.

Comparison of Sero-Status With Renal Leptospira Infection Front Vet Sci. 7:106. https://doi.org/10.3389/fvets.2020.00106 
Bharti A. R. (2003) Leptospirosis: a zoonotic disease of global importance. The Lancet Infectious Diseases. 3:757-771. https://doi.org/10.1016/S1473-3099(03)00830-2

Bhuyar P., Rahim M.H., Sundararaju S., Maniam G.P., Govindan N. (2020) Antioxidant and antibacterial activity of red seaweed Kappaphycus alvarezii against pathogenic bacteria. Global Journal of Environmental Science and Management. 6(1): 47-58.

Faine S., Stallman N. D. (1982) Amended Descriptions of the Genus Leptospira Noguchi 1917 and the Species L. interrogans (Stimson 1907) Wenyon 1926 and L. biflexa (Wolbach and Binger 1914) Noguchi 1918. International Journal of Systematic and Evolutionary Microbiology. 32(4):461-463. https://doi. org/10.1099/00207713-32-4-461

Hasbi M. A., Pragas G. M., Govindan N. (2021) Isolation and characterization of bioactive compounds in medicinal plant centella asiatica and study the effects on fungal activities. Journal of microbiology, biotechnology and food sciences. 10 (4):631-635. https://doi.org/10.15414/jmbfs.2021.10.4.631-635

Hulai O.V. (2003) Biokhimichni zviazky Leptospira interrogans z fonovymy vydamy alhoflory akvatsenoziv Tsentralnoi Ukrainy. Naukovi zapysky Ternopilskoho derzhavnoho pedahohichnoho universytetu im. Volodymyra Hnatiuka. Seriia: Biolohiia. 1 (20): [The biochemical relations of Leptospira interrogans with the background species of the algoflora in aquatic ecosystems at the cental Ukrainian region]. 77 - 80. (in Ukrainian).

Hulai O.V. (2005) Konsortyvni zviazky spirokhet Leptospira interrogans u pryberezhno-vodnykh ekosystemakh: Instytut ahroekolohii ta biotekhnolohii UAAN: [The consortal connections spirochetes Leptospira interrogans in the water and near bank ecosystems]. 154. (in Ukrainian).

Hulai O.V., Hulai V.V. Arkushyna H.F. (2010) Osoblyvosti ekolohichnykh vzaiemodii mizh predstavnykamy rodyny khvoshchi ta patohennymy leptospiramy $v$ umovakh perezvolozhenykh zemel. Naukovi zapysky Ternopilskoho natsionalnoho pedahohichnoho universytetu im. Volodymyra Hnatiuka. Seriia: Biolohiia. 4 (45): [Peculiarity of ecological interactions among representatives of family equisetaceae and pathogenic leptospires in the conditions of wetlands territories]. 127 - 131. (in Ukrainian).
Levett P. N. (2001) Leptospirosis. Clinical Microbiology Reviews. 14: 296-326. https://doi.org/10.1128/CMR.14.2.296-326.2001

Mahtab M., Khan F., Azam M., Rizvi M., Sultan A., Shukla I., Almatroudi A. (2019) Molecular characterization and phylogenetic analysis of human pathogenic Leptospira species circulating in a tertiary care hospital of Western Uttar Pradesh in India. Pathog Glob Health.113(6):275-281. https://doi.org/10.1080/2047 7724.2019 .1685196

Ngugi J.N., Fèvre E.M., Mgode G.F., Obonyo M., Mhamphi G.G., Otieno C.A., Cook E.A.J. (2019) Seroprevalence and associated risk factors of leptospirosis in slaughter pigs; a neglected public health risk, western Kenya. BMC Vet Res. 15(1):403.https://doi. org/10.1186/s12917-019-2159-3

Philip N., Bahtiar Affendy N., Ramli S.N.A., Arif M., Raja P., Nagandran E., Renganathan P., Taib N.M., Masri S.N., Yuhana M.Y., Than L.T.L., Seganathirajah M., Goarant, C., Goris M.G.A., Sekawi Z., Neela V.K. (2020) Leptospira interrogans and Leptospira kirschneri are the dominant Leptospira species causing human leptospirosis in Central Malaysia. PLoS Negl Trop Dis.14(3):e0008197. https://doi.org/10.1371/journal.pntd.0008197

Piredda I., Nicoletta Ponti M., Palmas B., Noworol M., Pedditzi A., Rebechesu L., Chisu V. Molecular Typing of Pathogenic Leptospira Species Isolated from Wild Mammal Reservoirs in Sardinia (2021). Animals (Basel) 11 (4):1109. https://doi. org/10.3390/ani11041109

Trop I.E. (1976) 0 prichinakh snizheniya chastoty leptospironositelstva u melkikh mlekopitayushchikh v prirodnykh ochagakh. Tezisy dokladov Vsesoyuznoy nauchnoy konferentsii po leptospirozu: [On the reasons for the decrease in the incidence of leptospirosis in small mammals in natural foci]. 127-129. (in Russian).

Vinetz J. M. (2001) Leptospirosis. Current Opinion in Infectious Diseases. 14: 527-538. https://doi.org/10.1097/00001432200110000-00005

Xiao-Juan Ma, Xiao-Qing Gong, Xiao Xiao, Jian-Wei Liu, Hui-Ju Han, Xiang-Rong Qin, Si-Cong Lei, Xiao-Lan Gu, Hao Yu, XueJie Yu (2020) Detection of Leptospira interrogans in Hedgehogs from Central China. Vector Borne Zoonotic Diseases. 20 (6): 427-431. https://doi.org/10.1089/vbz.2019.2544 